\title{
Forensic Expertise of the Traces of Break-in Instruments
}

\author{
Chera Marilena Cristina \\ “Alexandru Ioan Cuza” Police Academy, Bucharest, Romania, marilenachera@yahoo.com
}

\begin{abstract}
There are many crimes that implicate different instruments that can leave contact traces. For making a felony against patrimony, such as theft, housebreaking or destruction, the offender needs instruments to get in certain polices or areas by forcing or breaking the objects that block the access to those areas. The felons can use simple instruments like those for material processing or they can use instruments that they built. The forensic expertise of instruments traces can figure out the nature of type of instrument they used, the mechanism of the breaking and succession of facts for accessing a patrimony. The expertise can also say if there were one or more instruments. Analyzing the mode of operation and the procedures used during the crime, the expertise can determine the number of persons involved in the felony.
\end{abstract}

KEYWORDS: break-in instruments, forensic expertise, probation, traces

\section{Introduction}

Many crimes committed imply using different instruments that leave contact traces. Most are used in burglary actions as a way of breaking in rooms, forcing the places where goods are kept and unlocking or removing of locks. For this are used usual tools meant to work the materials, or especially made instruments (Buzatu 2013, 70).

Break-in instruments are all devices, installations, objects, instruments or other such means used or meant to use for breaking in rooms, means of transport, etc, or unlocking furniture pieces, safe deposits, locks, etc. (Ionescu 2008, 169).

In the category of break-in instruments are included crowbars, levers, picks, screwdrivers, grabber, drills, saws, wrenches, etc., and tools, adapted or especially made instruments.

Depending on the nature and the way of acting of instruments, the traces are formed by cutting, scraping, pressing, hitting, pricking, melting, burning, etc., and can be static, dynamic, depth and surface. The cutting traces are dynamic and are due to the action of the cutting instrument. By cutting, in the trace is reproduced the exterior micro-relief of the blade and the side parts of the used instrument (lakubovskaia, 1964).

As a result of forcing different obstacles, the used instruments may leave scraping - sliding traces, which have a dynamic character, whether depth or surface, of deformation or partial destruction of the material. The instruments used in this situation are: saw, files, hack saw or other instruments in this range that leave jag or striation trace. In the case of such traces, the exterior form of the instrument used cannot be impressed, but the dynamic character of the trace from which the striations result constitutes an important element in the individual traceological identification. The traces left by scraping- sliding are typical in case of forcing the lock-unlock systems with suitable keys or picklocks. By introducing into the lock system a suitable key or a picklock, by turning them, one can act differently than with the original key on mortises or other mechanisms, forming some specific traces, in the form of scratches, in such situations, on the occasion of the view, there are not any attempts (trials) with the original key in lock systems, because they can damage or deteriorate the traces left by the suitable key or the picklock.

The pressing traces are met in case of forcing the access points to rooms, pieces of furniture, etc, and are created by levers, crowbars, screwdrivers, or especially made devices. There are static depth traces and can be used only at the group identification of the creator object.

The traces formed by hitting are characteristic to some instruments like hammers, axes, crowbars, etc., and can be static or dynamic, surface or depth. Depending on the nature of the instrument used, the form of the trace of hitting can be different. When the blade of an axe hits, less deep or deeper fissures in the object will appear, depending on the intensity of the hit and the hardness of the object.

In case instruments that leave pricking traces that act with a certain usable surface (knitting needle, screwdriver points, knife points, corkscrew, needles, etc) are used, the so-called depth traces 
are created. The traces formed by pricking can be found on different bases, like: wood, metal, wall, and other fix or mobile objects that will have a relatively flat aspect, retaining a part of the external characteristics of the creator object. The traces of burning and melting indicate the m.o. used in committing the crime. When they are left on the body, clothes and shoes of the perpetrator, they can serve to the individual identification of the perpetrator.

Examining the traces of instruments during the view of the crime can end with many useful information in order to guide the evidence response team in the elaboration and verification of the versions relative to the circumstances of committing the crime and the person of the perpetrator.

\section{Particularities of searching, finding out, fixing and picking up traces of break-in instruments}

The identification value of the traces depends on the fidelity with which the receiving object reproduces the macro or micro-relief of the active part of the instrument used. The forensic expertise of the traces of instruments allows sometimes only to establish the type of the creator object, and other times its individual identification.

Forcing the access ways to rooms. The procedures used are reflected in the type of the traces left by the break-in instruments, these indicating the degree of specialization of the burglar.

Forcing the doors is done by destroying the panel, pulling or unlocking the lock systems with various devices or by pressing with different instruments used as levers. At the moment of forcing, on doors and edges depth traces are formed due to the compression of the wooden material under the pressure done by the instruments used by the burglar. Sometimes also cutting traces can be found out when from the panel of the door the portion that contains the lock was cut out (Ionescu 2008, 170).

During the view other categories of traces must be found out and picked up, like papillary, ear, particles of paint left on the scene or taken from this place by the instruments used, traces of blood, threads and fabric fibers of other material trash like sawdust, iron filings, etc.

Forcing the windows and windowpanes is done by dislocating the frame and cutting or breaking the windowpane. In order to separate the frame, a thin and bent point lever is used with which one acts on the edge and the frame of the window. The traces that are formed are generally depth or break traces. The windowpane can be separated by dislocating the sealing substance or the slat that fixes it with a knife or a chisel. On the frame and the sealing substance remain traces of the forcing instrument, and on the interior and exterior surface of the windowpane, papillary traces.

Breaking the walls, ceilings and floors is done with picks, chisels, different corrosive substances and even explosive materials. By the breach created, one can enter the room and then take out the goods aimed at in order to commit the crime.

Forcing the pieces of furniture - are forced those objects in which goods or values are kept, like safe deposits, wardrobes, cabinets, chests of drawers, suitcases, bags, handbags, etc, most of the times one acts on the locks, and if they cannot be unlocked, crowbars, levers, knives, etc. are used, the traces left at the moment of enforcement are found near the locks.

\section{Finding out, fixing, picking up and interpretation of traces}

After they would have been found, they will be carefully picked up, investigated and preserved in order to use them as evidence, because any offence, irrespective of its gravity, is accompanied by leaving some "traces" at the place of its commission. Studying the traces created by committing the crimes is very important in investigating the criminal cases, because on the basis of the totality of the traces left by the offender, often the content of different episodes of the crime is elucidated, and in some cases, even the whole picture of the crime committed.

Fixing the traces is done by the report and by photographing (the procedure of shadow photographing).

Picking up the depth traces is done through molds (plaster, plasticine etc.).

Interpretation of the traces offers data regarding the nature of the criminal act, the type of instruments used and the m.o. of the perpetrator.

Comparing traces, incriminated and experimental, allows to establish the identity, or, on the contrary, non-identity. Whether the molds between them are compared, or the photos between them, 
or both. The evidence of identity is given by the linear continuity of the striations, at the comparing microscope, or by juxtaposing the photos taken separately (Buzatu 2013, 70).

\section{Problems that can be solved by forensic expertise of the break-in instruments}

Traces of instruments corroborated with other categories of traces found on the scene and with the information collected by the plaintiff, victim, eye witnesses or other sources can offer data about (Ionescu 2007, 87):

- m.o. used at the commission of the crime;

- the nature of the instruments used;

- the form and dimension of instruments that left traces;

- the direction in which it was acted with these instruments;

- the number and order of creating the traces; if all the traces were created with the same instrument;

- clarifying some controversial circumstances, regarding the commission of the crime (known in the speciality literature under the name of "negative circumstances");

- elaboration of some elements necessary to form the suspects;

- estimating the time the activity of the offender lasted at the crime scene;

- identification of the instrument that left the trace.

The traseological expertise has as purpose the identification of objects that created the traces found at the crime scene in case of investigating different types of crimes. The litigious traces are examined, picked up on the scene by photographing, mold or objects that have traces, in comparison with the experimental models created by the forensic expert with the help of the objects supposed to have been left at the crime scene. The forensic expertise of the traces formed by the break-in instruments when committing a crime helps to find the answers regarding the nature and the type of the instruments, and also the mechanism of forming the trace and their succession. Also, by expertise it can be established if the trace belongs to one instrument or many. Depending on the m.o. and the procedures used, the number of persons that participated in committing the crime can be determined. The expertise of the traces formed from material waste (sawdust, filing, paint layers, splinters, drops of melted metal, etc.) can determine both the nature, the chemical composition of the material, and its belonging to the broken object or the instrument used. When making such type of expertise, usually, are used: optical devices (magnifying glass, monocular, binocular microscope, or stereomicroscope S.M. The purpose the camera), palpation devices (Profilograph, Striagraph, Striation Tracer).

The main problem of the expertise of the break-in instruments represents their identification. For this reason, obtaining the comparison models is important, it is recommended to be done on materials which are similar as quality to the object that has a trace. Especially in case of some cutting instruments, because of using them subsequently, for other purposes, including for making comparison models, it is possible to modify the relief of the blade. That is why, it is more indicated to proceed as urgent as possible to pick them up from the suspects, in order to be sent to be examined to the forensic expert.

\section{Conclusions}

In order to reach their goal, the aggressor or the offender resort to different break-in instruments. Listing these instruments is impossible because it differs from case to case, and the offender becomes inventive when they want to reach their goal. Because of the variety of these instruments, both of nature, size and form, the traces created by using them are numerous.

Most frequently the offenders act on the locks or hatches with suitable keys, various picklocks or lock picks, a procedure applied by experienced perpetrators as being the most silent way and leaving the least traces. In this case, the traces are left inside the lock, which means examining it in the laboratory, and the legal authority must limit only to the interior examination of the lock. Depending on the model of the lock (locks or bolts), the easiest to unlock are the simple ones, followed by those with mortises or safety those based on pins (locks with cylinder), which are safer. 
Breaking in a window is quite usual in order to break in a room or building and in this case the traces of forcing are the characteristics of the m.o. A window can be forced by breaking the windowpan or dislocating the frame. Dislocating is done with the following instruments: lever or crowbar which leave traces by pressing or breaking. The perpetrators, in order not to get attention too much, want to operate quietly, resorting to cutting the window with a diamond, enough to introduce the hand and open the window. They are very careful to details and thought in the following way, so that the windowpan not fall and make noise, they stick on them a sticking plaster, a self-adhesive or a paper, the surface of which being glued, etc.

In the technique of using the sticking plaster, the windowpan can be broken by pressing, without needing to be cut. In all cases the splinters have finger prints, and the type and nature of the sticking plaster help identify the offender. At present because of the multitude of cases, we find that the breaking in is not only through the door or window. In the specialty practice, there are cases of breaking in through wall, roof, ceiling or booth, which means that the offender knows the field, especially they analyzed very well where they can break in the room.

Finding the traces of break-in instruments is possible, generally, by simply examining to the naked eye, and in some cases with a magnifying glass and a good source of light.

Examining shall be made only by the forensic expert. Fixing the traces on the instruments with which it was acted is done by describing in the report of the view, photographing and molding. Molds are made of paraffin wax or red wax, those of plastic or plaster are rarely used. Before applying the mold, glycerin is applied, so that the mold does not adhere to the substance of the receiving object.

Most frequently, the aggressors act in cases of crimes committed outside. They assault especially old people that cannot defend themselves because of their age, children, sick people, etc. They appear before people with an object or a cutting weapon in order to scare people when they ask them the expensive things they have with them (money, necklace, earrings, rings, bracelet). The aggressor does not want to hurt the victim with that weapon, only to scare the victim. There are cases when, because of despair, the aggressor stabs or kills the person, and all these because of despair that the victim does not submit to his requirements. In this case, the aggressor is identified by the authorities by the description made by the victim, how and in what way the crime happened.

Theft from crowded places is the suitable place in which an offender can commit more easily the crime, taking advantage of people's inattention. The same is in the case of stealing luggage. Stealing from cars is done during night and in places without much light, analyzing what expensive objects/ things are in the car. Generally the tape player, the acronym, the mirrors, the wheel trims, side blinkers, etc., of the car are stolen. Stealing from hotel rooms is done by breaking the deadbolt lock. The offender slips in the hotel very carefully, analyzes people, the rooms that they leave, and thus fixing the victim.

While committing a crime, it is almost impossible that the offender commits ,the perfect crime", because he can leave traces, indices on the scene without realizing it. Both the aggressor, and the offender analyze very well the victim, the things they can steal from them, and they think about their way of acting. They know very well the break-in instruments they use, and the weapons with which they threaten the victim.

\section{References}

Buzatu N.-E. 2013. Forensics. Bucharest: Pro Universitaria Publishing House.

Iakubovskaia I. 1964. "Some aspects of identifying cutting traces," in Judicial and forensics medical issues, vol I. Bucharest: Medical Publishing House.

Ionescu F. 2008. Forensics. Bucharest: Universitara Publishing House.

Ionescu L. 2007. Forensics. Bucharest: Pro Universitaria Publishing House. 